\title{
Microwave-induced low temperature pyrolysis of macroalgae for unprecedented hydrogen-enriched syngas production
}

Jose M. Bermúdez ${ }^{\mathrm{a}}$, Matteo Francavilla ${ }^{\mathrm{b}, \mathrm{c}}$, Esther G. Calvo ${ }^{\mathrm{a}}$, Ana Arenillas ${ }^{\mathrm{a}}$, Massimo Franchi $^{\mathrm{c}}$, J. Angel Menéndez ${ }^{\mathrm{a} *}$, Rafael Luque $^{\mathrm{d} *}$

${ }^{a} I N C A R-C S I C$, Apdo.73, 33080 Oviedo,Spain.,email: angelmd@incar.csic.es ${ }^{b}$ STAR-Agroenergy Group, University of Foggia, via Gramsci 89/91, 71121, Foggia (ITALY).E-mail: m.francavilla@unifg.it; Tel: +39 3403927680.

${ }^{c}$ Institute of Marine Science, National Research Council, via Pola 4, 71010 Lesina (ITALY)

${ }^{d}$ Departamento de Quimica Organica, Universidad de Córdoba, Campus de Rabanales, Edificio Marie Curie, Ctra Nnal IV-A, Km 396, E14014, Córdoba, Spain. E-mail: q62alsor@uco.es; Fax: +34 957212066; Tel: +34957211050

\section{Abstract}

An efficient methodology based on low temperature microwave-induced pyrolysis has been developed for syngas production from macroalgae. The protocol provided an unprecedented hydrogen production, with switchable $\mathrm{H}_{2} / \mathrm{CO}$ ratios depending on pyrolysis conditions which were found to remarkably improve conventional pyrolysis experiments even at significantly higher temperatures $\left(400\right.$ vs $\left.800^{\circ} \mathrm{C}\right)$. Arcing effects under microwave irradiation as well as an interestingly observed pseudo-catalytic reforming effect of metal oxides contained in macroalgae seem to account for the improved results. 


\section{Introduction}

Biomass research as alternative feedstock to fossil fuels is intensifying in recent years due to its important role in reducing $\mathrm{CO}_{2}$ emissions and the promotion of environmentally acceptable practises. Many technologies are currently under investigation for biomass utilisation both for power generation, biofuels and chemical commodities production. ${ }^{1}$

Marine origin biomass (e.g. seaweed) has attracted considerable attention as a potential biofuel feedstock. ${ }^{2}$ Seaweeds are important components in marine ecosystems providing essentially unique ecological functions. ${ }^{3}$ Algae have a number of desirable features including fast growth, high biomass conversion rate, short growth cycle, ease of handling and reduced potentially-zero net $\mathrm{CO}_{2}$ emissions. ${ }^{4}$ The average photosynthetic efficiency of aquatic biomass (ca. 6-8\%) is remarkably superior to that of terrestrial biomass (typically $1.8-2.2 \%$ ). ${ }^{5}$ Additional advantages for algal feedstocks also include the absence of competition with conventional agriculture for land, the possibility to utilize various unconventional water sources in their growth (e.g., seawater, brackish water and wastewater), a potential recycling of carbon dioxide as well as an interesting potential compatibility with integrated production of fuels and co-products within biorefineries. ${ }^{6,7}$

Seaweed production is mostly divided into two types across the globe: naturally and artificially/marine farmed produced species. Asian countries generally follow the molecular farming strategy to achieve different types of algal species while European countries obtain seaweed from natural or wild habitats. Importantly, seaweeds constitute a promising and already economically valuable resource, currently employed in a range of applications such as food additives, fodder, manure, medicine, industrial raw material and nutrient remover. ${ }^{8,9}$ 
Importantly, somewhat related types of algae species (e.g. algal blooms) originate as a consequence of euthrophication due to an increase of nutrient input, mainly nitrogen and phosphorus. ${ }^{10}$ There are significant concerns around such algal blooms due to their potential production of toxins (e.g. microcystins) as secondary metabolites which can have significant effects in the growth and development of agricultural and biological environments. ${ }^{11}$ The management of such algal blooms is in fact an important issue that has rarely been addressed in detail to date in a different way to disposal and/or landfilling.

In the perspective of exploiting macroalgae and particularly algal residues as biofuel feedstock, several studies have been conducted in order to convert marine biomass into biofuels via different processes including Anaerobic Digestion (AD) for biogas production, ${ }^{4}$ bioethanol, ${ }^{7,9}$ and bio oil. ${ }^{2}$ Interestingly, less attention has been devoted to thermochemical conversion of seaweeds into biofuels. ${ }^{12}$ The different thermochemical options for macroalgae utilisation include direct combustion, gasification, pyrolysis and liquefaction. Ross et al. investigated thermal treatment of five macroalgae (Fucus vesiculosus, Chorda filum, Laminaria digitata, Fucus serratus, Laminaria hyperborea, and Macrocystis pyrifera) and their suitability for different thermal routes. ${ }^{12}$ They concluded that ash content and chemistry itself restricted the use of macroalgae for direct combustion and gasification. Hydrous pyrolysis or digestion methods, more tolerant to the ash components in the fuel, were suggested as potentially appropriate for seaweed valorisation to fuels and chemicals. In a more recent study, Trinh et al. demonstrated that fast pyrolysis performed in a pyrolysis centrifugal reactor (PCR) at low temperatures (as compared to combustion and gasification) was not remarkably affected by slagging, fouling, and aerosol formation, problems essentially 
related to ash content. ${ }^{13}$ Macroalgae pyrolysis (Ulva lactuca species) were eventually found to exhibit promising results in terms of bio-oil yield and energy recovery. ${ }^{13}$ Microwave mediated pyrolysis of seaweed has comparably been only recently tested on Gracilaria gracilis $^{14}$ and Ulva prolifera ${ }^{15}$ aiming to maximise bio-oil yields, with no characterization performed on produced syngas. Most importantly, the oils obtained in algal pyrolysis are acidic, unstable, viscous, include chemically dissolved water and have high proportions of nitrogen compounds, ${ }^{15,}{ }^{16}$ a series of undesirable features which require additional bio-oil upgrading post-treatments. In the light of these premises, processes focused on gas generation from pyrolysis of algal biomass and residues could offer a promising alternative to direct biofuels production (e.g. syngas). Microwave induced pyrolysis has shown an exceptional ability to maximise gas production in the pyrolysis of various feedstocks including sewage sludge, glycerol or coffee hulls, even at low temperatures. ${ }^{17,18}$ In addition, the outstanding quality of the gas produced in microwave induced pyrolysis (featuring high proportions of $\mathrm{H}_{2}$ and syngas as compared to conventional pyrolysis) as well as the possibility to conduct the process at significantly reduced temperatures make this process even more attractive. Moreover, it has been recently reported a mechanistic study of the interaction between microwave irradiation and cellulose (one of the main components of Gracilaria cell wall) which explains, among other findings, different experimental observations such as high efficiency of microwave treatment. ${ }^{19}$

Herein, we report an unprecedented production of hydrogen-enriched syngas with tuneable $\mathrm{H}_{2} / \mathrm{CO}$ ratios from Gracilaria gracilis, a macroalgae grown in the Lessina lake in Italy to remove the previously mentioned eutrophication problem. Syngas production could be simply achievable from Gracilaria via low temperature microwave induced 
pyrolysis (MIP). Gas production and composition using the MIP methodology was compared to those obtained under conventional thermal pyrolysis (CP). To the best of our knowledge, this is the first example of a comparison between microwaves and conventional heating for algal pyrolysis focusing on syngas production as well as the first technology able to provide a sustainable direct solution to the valorisation of algal blooms different from photocatalytic degradation or removal of cyanotoxins generated by such algae. ${ }^{20}$

\section{Materials and Methods}

\subsection{Gracilaria sampling}

The red seaweed Gracilaria gracilis was collected from the western area of the Lesina lagoon, where a stable assemblage of this seaweed grown to remove the significant eutrophication issue of the lake was found $\left(41.866470^{\circ} \mathrm{N}, 15.363350^{\circ}\right.$ E). About $1 \mathrm{Kg}$ of wet biomass was sampled in July 2011. Algal biomass was washed with distilled water and their epiphytes removed. The fresh seaweed was placed in a freezer $\left(-20^{\circ} \mathrm{C}\right)$ immediately after collection. The cleaned seaweed was freeze-dried at $-110^{\circ} \mathrm{C}$ to preserve the algae for future analysis and then ground to fine powder and stored in airtight containers at $-20^{\circ} \mathrm{C}$. The biochemical composition of macroalgae is summarised in Table 1. 
Final version published in RSC Advances, 2014, 4 (72), 38144-38151

Table 1. Biochemical composition (\% d.w.) of Gracilaria gracilis sampled in the Lesina lagoon (Italy).

\begin{tabular}{ll}
\hline Total Lipids & 1.98 \\
Fatty Acids Methyl Esters & 0.47 \\
Proteins & 30.93 \\
Carbohydrates & 27.54 \\
Ashes & 27.89 \\
\hline
\end{tabular}
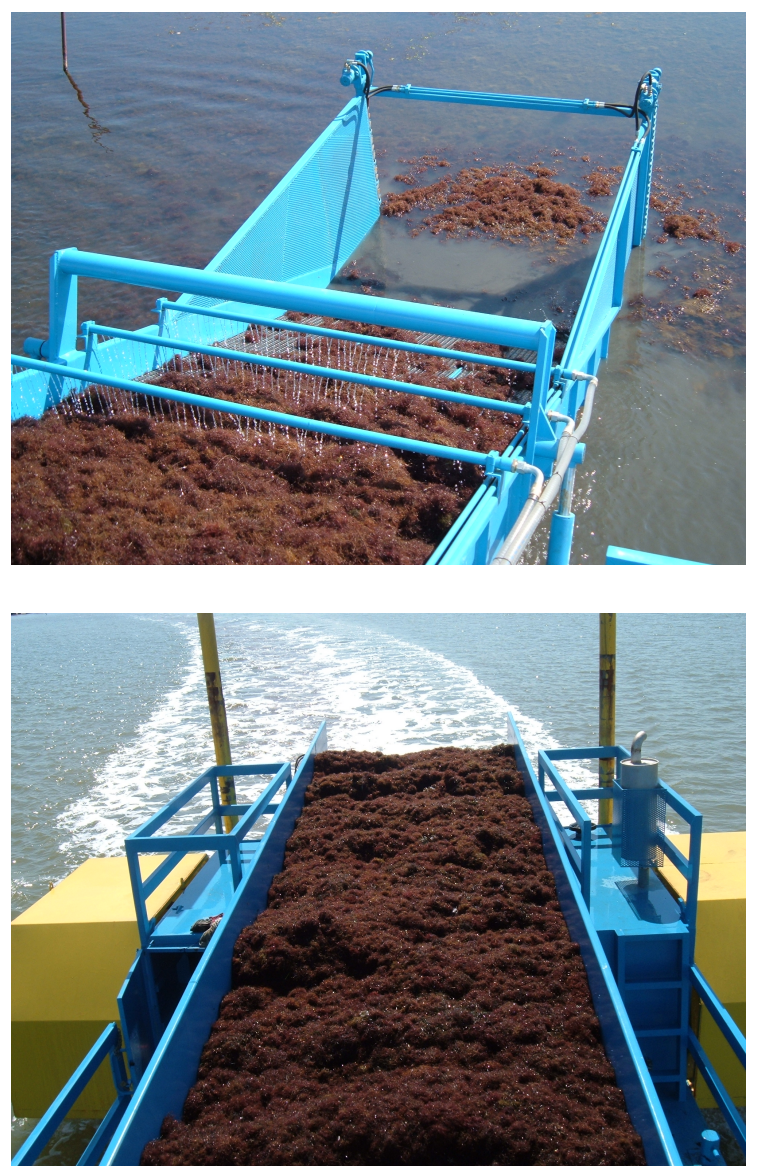

Figure 1. Mechanical harvesting process of Gracilaria gracilis in the Lesina lagoon (Italy).

\subsection{Experimental procedure}

Seaweed pyrolysis was conducted in two different heating devices: a conventional electrical furnace for CP and a single mode microwave oven for MIP. The microwave oven uses a magnetron of a maximum power of $2 \mathrm{~kW}$ to generate the microwave 
radiation. Three different pyrolysis temperatures $\left(400,600\right.$ and $\left.800{ }^{\circ} \mathrm{C}\right)$ were screened in both CP and MIP (Table 2).

Experiments were performed as follows: $4 \mathrm{~g}$ of macroalgae sample were introduced into a quartz reactor and degassed under a helium flow (100 mL STP $\left.\mathrm{min}^{-1}\right)$

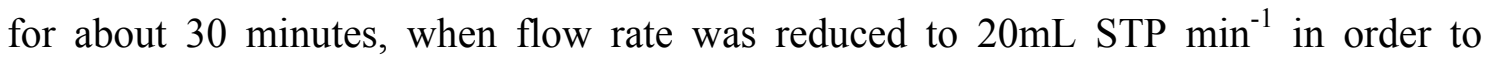
perform the pyrolysis experiments. In the case of MIP, a mass of ca. $1.2 \mathrm{~g}$ of microwave absorber was also added to the feedstock prior to commencing the pyrolysis. Biomass is in fact a poor microwave absorber. ${ }^{18}$ Moreover, a blank experiment without any microwave absorber was performed, finding that the macroalgae were not heated to more than $120^{\circ} \mathrm{C}$ by microwave irradiation. Therefore, a material able to absorb the initial microwave radiation in order to reach the temperature required to perform the pyrolysis experiments was added. The char obtained in the process of algae CP (pyrolysis temperature: $800{ }^{\circ} \mathrm{C}$ ) was originally added as microwave captor in MIP to avoid the use of a material with very different properties to those of algae. A $30 \mathrm{wt} \%$ of microwave absorber captor (mw captor/biomass sample: 30/70, $1.2 \mathrm{~g}$ ) was selected as optimum for MIP experiments based on experimental data and previous experience of the group. Quantities of microwave absorber lower than $30 \mathrm{wt} \%$ were unable to provide reproducible results due to issues related to homogeneous heating in microwaveassisted pyrolysis experiments (see ESI for full details). Additionally, powdered graphite was used as mw absorber in a comparative experiment under otherwise identical conditions to those detailed before.

The insertion of the quartz reactor with the sample was different depending on the heating device used. In the case of $\mathrm{CP}$, the pyrolysis temperature is firstly set and the reactor with the seaweed is placed inside the furnace once the furnace starts to heat to 
the desired temperature (monitored by means of a type $\mathrm{K}$ thermocouple). Comparatively, the reactor was placed in the centre of the microwave guide prior to starting microwave radiation in MIP as in this case the needed time to reach the pyrolysis temperature is very short (about 2-5 minutes). Unlike electric furnaces, there are limitations when a thermocouple type $\mathrm{K}$ is used in microwave devices. ${ }^{21}$ Therefore, the temperature is monitored by an infrared optimal pyrometer for microwave-induced pyrolysis (MIP).

Macroalgae pyrolysis results in three different fractions: solid, liquid and gas. The liquid fraction is recovered from a condensation system cooled down with a cryogenic solution formed by a mixture of water and sodium chloride. The residue content in the condensation system is dissolved in dichloromethane and the liquid fraction is obtained upon evaporation of the solvent at $40{ }^{\circ} \mathrm{C}$. The composition of the oil fraction has not been analysed in this work. The non-condensable gases are collected in Tedlar ${ }^{\circledR}$ bags (at 10 minutes intervals) with a propylene fitting for sampling and subsequently analysed in a Varian CP-3800 gas chromatograph. In order to determine pyrolysis yields, the solid and bio-oil fraction yields were calculated from the weight of each fraction whereas the gas fraction was determined by difference. The composition of the gaseous fraction was determined from the composition of each Tedlar ${ }^{\circledR}$ bag and the He flowrate (which is constant throughout the experiment at the inlet and the outlet of the reactor because He cannot be produced or consumed in the pyrolysis process). With this composition and the weight of gas, the total gas production can be calculated. In the case of the solid fraction, the microwave receptor mass was not accounted for the yield calculation. The total time required to complete the pyrolysis experiments was selected according to the outlet flow rate of the pyrolysis gases. The pyrolysis is 
finished when the flow rate of the pyrolysis gases was less than the $3 \%$ of the helium flow (0.6 $\left.\mathrm{mL} \mathrm{STP} \mathrm{min}^{-1}\right)$.

Table 2. Summary of pyrolysis experimental conditions tested in this work.

\begin{tabular}{lccc}
\hline \multicolumn{1}{c}{ Reference } & Heating device & Temperature $\left({ }^{\circ} \mathrm{C}\right)$ & MW absorber \\
\hline 400CP & Electric furnace & 400 & None \\
400MIP & Microwave oven & 400 & Pyrolysis residue 70:30 wt.\% \\
400MIP-G & Microwave oven & 400 & Graphite 70:30 wt.\% \\
400MIP-50C & Microwave oven & 400 & Pyrolysis residue 50:50 wt.\% \\
600MIP & Microwave oven & 600 & Pyrolysis residue 70:30 wt.\% \\
800CP & Electric furnace & 800 & None \\
800MIP & Microwave oven & 800 & Pyrolysis residue 70:30 wt.\% \\
\hline
\end{tabular}

\section{Results and Discussion}

The present work was aimed to maximise syngas and particularly hydrogen production as compared to bio-oil from the microwave-induced low temperature pyrolysis of macroalgae residues. Figure 2 shows the yields (expressed in mass percentage) of the different fractions obtained in the pyrolysis experiments. MIP maximises the gaseous fraction, both at high and low temperatures, with a maximum gas production of $63-65 \%$. The solid fraction was comparatively maximised at low temperatures in $\mathrm{CP}$ experiments (35-48\%), while larger quantities of bio-oil were obtained at high pyrolysis temperatures. In contrast, larger quantities of both liquid and solid phases were produced under $\mathrm{CP}$. 


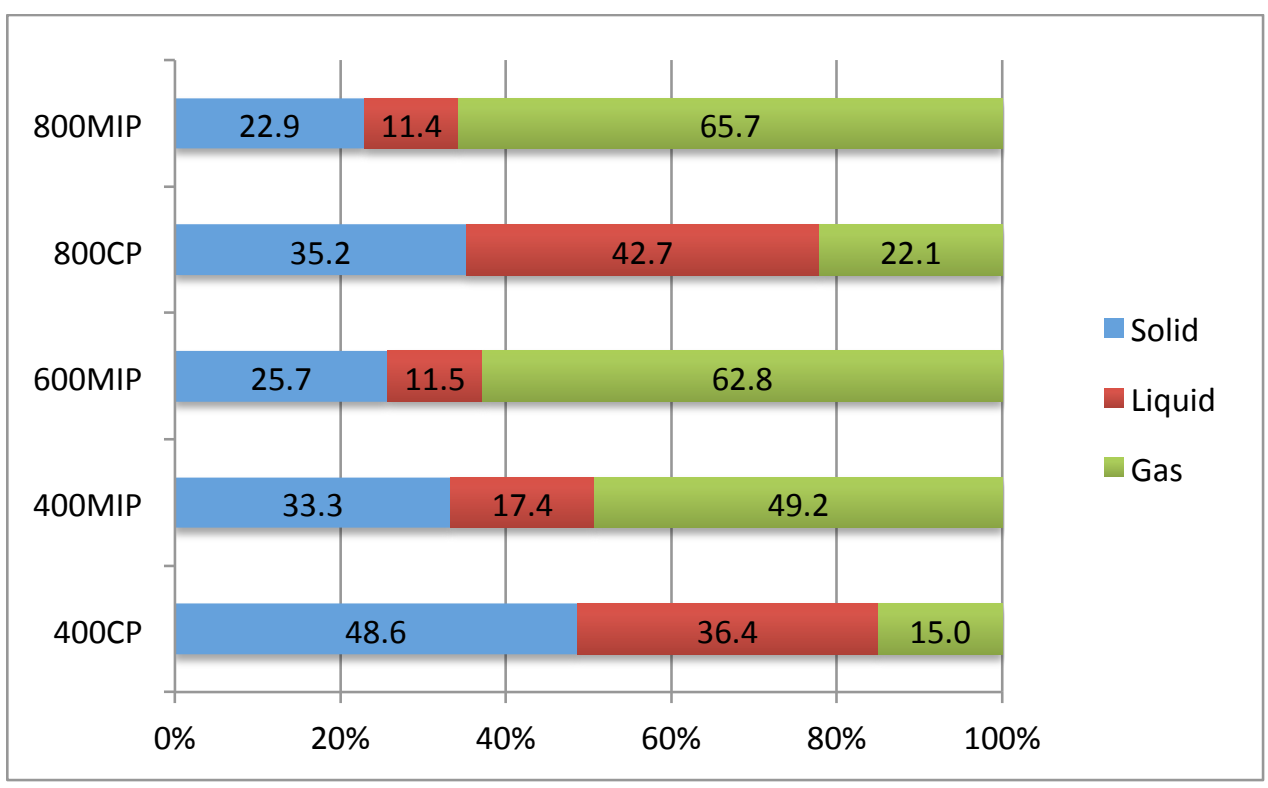

Figure 2. Yields of the different fractions obtained in the pyrolysis of macroalgae

Figure 3 depicts the cumulative gas production in the various conducted experiments. Remarkable differences were observed between CP and MIP, being interestingly more significant at low temperatures. MIP produces ca. 8 times more gaseous products as compared to $\mathrm{CP}$ at $400^{\circ} \mathrm{C}$; Figure 3, solid vs discontinuous lines). Increasing pyrolysis temperature to $600^{\circ} \mathrm{C}$ or $800^{\circ} \mathrm{C}$ reduces such differences (e.g. gas production is 4 times higher under MIP at $800^{\circ} \mathrm{C}$, Figure 3). Experiments also pointed out that there is no need to extend the pyrolysis process for a long time as gaseous production normally levels off at relatively short times of reaction (only low amounts of gas- $<5 \%$ extra- are produced at extended pyrolysis times, Figure 3). Optimum pyrolysis times range from 35-50 min under CP to ca. $70 \mathrm{~min}$ for microwave-assisted pyrolysis (see Figure $1 \mathrm{~S}$ and Table 1S in ESI for full details). The observed differences between CP and MIP were also reflected in the gas composition as clearly visible in Tables 3 and 4. 


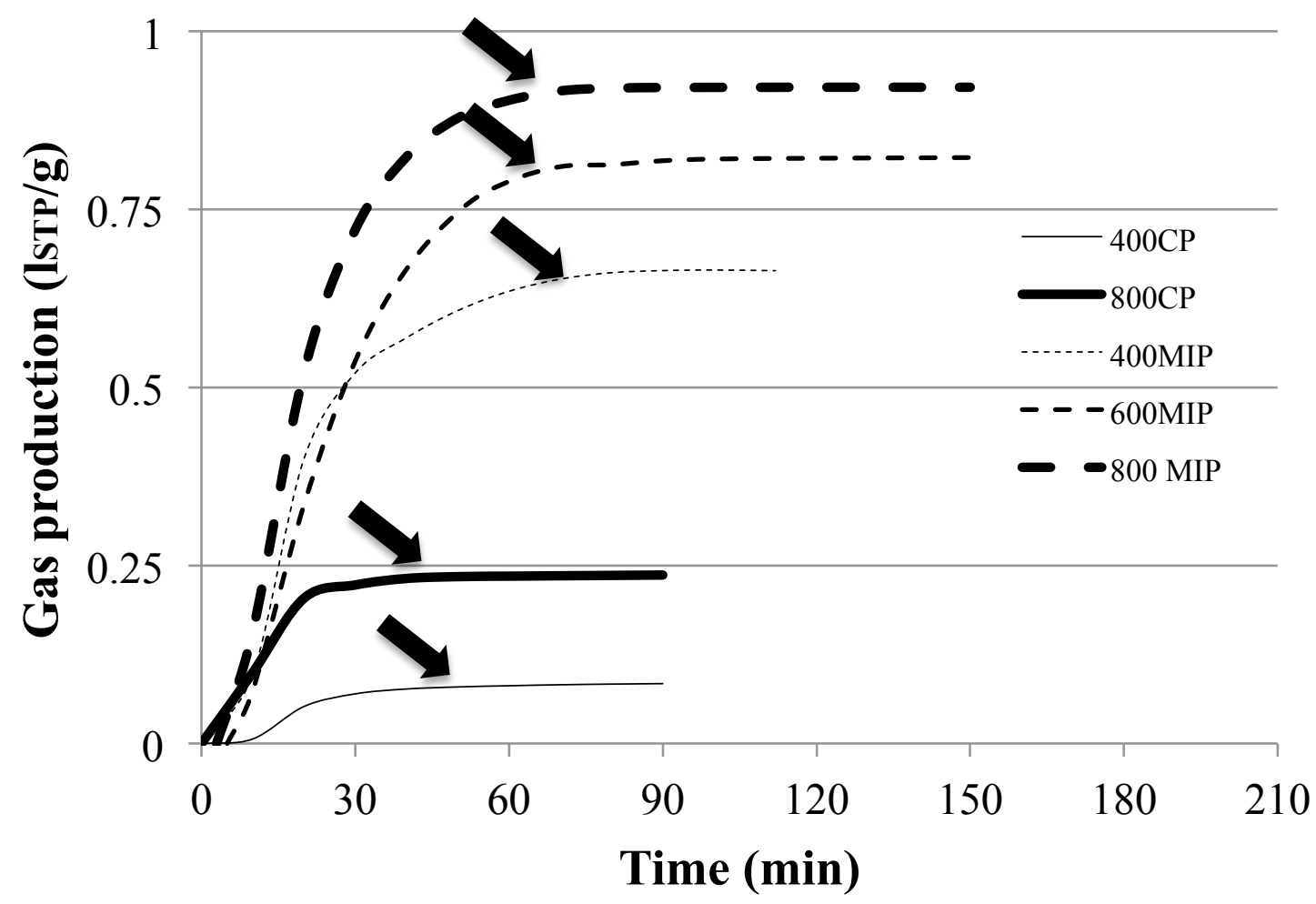

Figure 3. Cumulative gas production in the pyrolysis experiments at $400^{\circ} \mathrm{C}$ and $800^{\circ} \mathrm{C}$ degrees in conventional pyrolysis $(400 \mathrm{CP}, 800 \mathrm{CP})$ and at $400^{\circ} \mathrm{C}, 600^{\circ} \mathrm{C}$ and $800^{\circ} \mathrm{C}$ in the microwave oven (400MIP, 600MIP, 800MIP). The arrows indicate the point at which the pyrolysis can be considered to be finished.

Table 3 summarises compositions of the gaseous fraction of the different pyrolysis experiments (see Figure $2 \mathrm{~S}$ in the ESI). Results demonstrate that the percentage of syngas $\left(\mathrm{H}_{2}+\mathrm{CO}\right)$ generated under MIP also is remarkably larger with respect to conventional (only $\mathrm{CO}$ was produced). Importantly, an interesting $\mathrm{H}_{2} / \mathrm{CO}$ ratio (3.01) was obtained at low MIP temperature $\left(400^{\circ} \mathrm{C}\right)$, with $\mathrm{H}_{2} / \mathrm{CO}$ ratios of ca. $1-1.2$ at increased temperatures (Table 3). Furthermore, an additional advantage of MIP relates to the superior hydrogen production as compared to $\mathrm{CP}$, particularly at low pyrolysis temperatures (Table 3, 400 MIP vs $400 \mathrm{CP}$ ). 
Table 3. Gas compositions (vol.\%) of the gaseous fractions obtained in macroalgae pyrolysis

\begin{tabular}{lccccc}
\hline & $400 \mathrm{CP}$ & $400 \mathrm{MIP}$ & $600 \mathrm{MIP}$ & $800 \mathrm{CP}$ & $800 \mathrm{MIP}$ \\
\hline $\mathrm{H}_{2}$ & - & 57 & 48 & 33 & 49 \\
$\mathrm{CH}_{4}$ & 4 & 2 & 2 & 11 & 1 \\
$\mathrm{CO}_{2}$ & 78 & 22 & 9 & 18 & 6 \\
$\mathrm{C}_{2} \mathrm{H}_{4}$ & 1 & 1 & 0 & 1 & 1 \\
$\mathrm{C}_{2} \mathrm{H}_{6}$ & 2 & 0 & 0 & 1 & 0 \\
$\mathrm{CO}$ & 15 & 19 & 41 & 36 & 43 \\
\hline Syngas & $15^{*}$ & 76 & 89 & 69 & 92 \\
$\left(\mathrm{H}_{2}+\mathrm{CO}\right)$ & & & & & \\
\hline $\mathrm{H}_{2} / \mathrm{CO}$ & 0 & 3.0 & 1.2 & 0.9 & 1.1 \\
\hline
\end{tabular}

*only $\mathrm{CO}$ was produced

Hydrogen and syngas production from macroalgal waste obtained under MIP conditions (Table 4) are unprecedently large as compared to any CP or MIP reports, particularly at $400^{\circ} \mathrm{C}$, but generally regardless of the pyrolysis temperature. To support this statement, a careful and comprehensive literature search was conducted to further compare results with literature results. Table 5 summarises $\mathrm{H}_{2}$ and syngas productions obtained in microwave-induced pyrolysis of a series of different feedstocks that can be found in the literature. As clearly evidenced from this table, results reported here are remarkably superior to most previously reported cases and only marginally comparable in the cases of rice straw (forcing conditions) and high temperature MIP of glycerol. Even the reported syngas production at $400^{\circ} \mathrm{C}$ under the investigated conditions was significantly larger as compared to many of the literature examples.

Importantly, MIP results at low temperatures $\left(400^{\circ} \mathrm{C}\right)$ clearly predate those obtained at high temperature conventional pyrolysis $\left(800^{\circ} \mathrm{C}\right)$ in terms of both $\mathrm{H}_{2}$ proportion and production (Table 3, 400MIP vs $800 \mathrm{CP}$ ), which illustrates the potential of MIP. In any case, a larger gas quantity was obviously produced at increasing temperatures. 
However, the most important feature of the proposed methodology relates to its high versatility and applicability to fine tune syngas composition $\left(\mathrm{H}_{2} / \mathrm{CO}\right.$ ratio $)$ for various types of chemistries depending on needs and demands (e.g. Fischer-Tropsch, methanol and/or oxygenates production and even as feed for bacterial fermentation) ${ }^{22}$ Such versatility is comparably difficult to achieve under CP conditions.

Table 4. Gas production $\left(1_{\mathrm{STP}} / \mathrm{g}\right.$ of algae) of the different components of the gaseous fractions obtained in macroalgae pyrolysis

\begin{tabular}{lccccc}
\hline & $400 \mathrm{CP}$ & $400 \mathrm{MIP}$ & $600 \mathrm{MIP}$ & $800 \mathrm{CP}$ & $800 \mathrm{MIP}$ \\
\hline $\mathrm{H}_{2}$ & 0.00 & 0.38 & 0.39 & 0.08 & 0.45 \\
$\mathrm{CH}_{4}$ & 0.00 & 0.01 & 0.01 & 0.03 & 0.01 \\
$\mathrm{CO}_{2}$ & 0.07 & 0.15 & 0.08 & 0.04 & 0.05 \\
$\mathrm{C}_{2} \mathrm{H}_{4}$ & 0.00 & 0.01 & 0.00 & 0.00 & 0.01 \\
$\mathrm{C}_{2} \mathrm{H}_{6}$ & 0.00 & 0.00 & 0.00 & 0.00 & 0.00 \\
$\mathrm{CO}$ & 0.01 & 0.13 & 0.34 & 0.08 & 0.40 \\
\hline Syngas & 0.01 & 0.51 & 0.73 & 0.16 & 0.85 \\
\hline
\end{tabular}

Reasons behind the reported unprecedented hydrogen evolution in MIP systems are believed to be related to two different contributions. Firstly, a pseudo-catalytic effect is likely to be present due to plasma and arcing phenomena observed in the course of the experiments under microwave irradiation. These effects, which do not take place at processing temperatures under CP conditions, have been previously reported in related pyrolysis chemistries as well as in metal-microwave interactions. ${ }^{23,}{ }^{24}$ These plasmas appear during microwave heating and create hot spots. In these points temperature can achieve values considerable higher than the means temperature of the bed. It resembles what happens during a lightning storm, where the temperature of the rays can achieve several thousands of Celsius degrees without affecting the mean temperature of the atmosphere. As a consequence, the molecules that cross these plasmas or electric arcs are ionized, giving rise to a completely different chemistry. For these reason, processes 
that are not thermodynamically favored, can take place when the microwave heating is used.

Nevertheless, an additional catalytic effect of the microwave absorber (pyrolysis residue) in MIP experiments cannot be ruled out as metals contained in such material could be not only responsible of the observed arcing and plasmas but also of related reforming reactions of the gaseous mixture. An experiment using pure graphite powder as microwave captor (in comparison to the pyrolysis biochar) was consequently designed in order to address this potential catalytic effect (see Figure 3S).

Table 5. Comparison of $\mathrm{H}_{2}$ and syngas production ( $1_{\mathrm{STP}} / \mathrm{g}$ of pyrolysed material) as well as $\mathrm{H}_{2}$ proportion (vol.\%) obtained in literature reports for MIP of different feedstocks.

\begin{tabular}{|c|c|c|c|c|c|c|}
\hline Feedstock & $\begin{array}{c}\text { Temperature } \\
\left({ }^{\circ} \mathrm{C}\right)\end{array}$ & $\begin{array}{l}\text { Syngas } \\
\text { production }\end{array}$ & $\begin{array}{c}\mathrm{H}_{2} \\
\text { production }\end{array}$ & $\begin{array}{c}\mathrm{H}_{2} \\
\text { proportion }\end{array}$ & $\begin{array}{l}\mathrm{H}_{2} / \mathrm{CO} \\
\text { ratio }\end{array}$ & Ref. \\
\hline Macroalgae & 400 & 0.51 & 0.38 & $57-19$ & 3.0 & this work \\
\hline $\begin{array}{l}\text { Sewage } \\
\text { Sludge }\end{array}$ & $600-1200$ & $0.21-0.53$ & $0.07-0.34$ & $22-50$ & $0.9-2.6$ & $\begin{array}{c}17,25,26, \\
27,28\end{array}$ \\
\hline Coffe Hulls & $500-1000$ & $0.40-0.61$ & $0.24-0.34$ & $36-40$ & $1.2-1.7$ & $17,25,29$ \\
\hline Waste Tires & $350-600$ & $0.14-0.16^{(a)}$ & - & - & - & 30 \\
\hline Rice straw & $400-550$ & $0.19-0.53$ & $0.06-0.40$ & $18-55$ & $0.5-4.2$ & 31 \\
\hline Glycerol & 800 & $0.88-0.90$ & $0.36-0.40$ & $33-35$ & $0.7-0.8$ & 18,25 \\
\hline Pine sawdust & $400-800$ & - & - & $17-30$ & $0.4-1.6$ & 32 \\
\hline $\begin{array}{l}\text { Corn-Wheat } \\
\text { stalk }\end{array}$ & $600-700$ & $0.25-0.27$ & $0.13-0.17$ & $35-37$ & $1.8-2.1$ & 33 \\
\hline Microalgae & $400-1250$ & $0.09-0.74$ & $0.06-0.40$ & $22-50$ & $1.1-2.3$ & 34 \\
\hline Macroalgae & 130 & $0.32^{(a)}$ & - & - & - & 14 \\
\hline $\begin{array}{l}\text { Douglas fir } \\
\text { sawdust }\end{array}$ & 330 & $0.07-0.15$ & - & - & - & 35 \\
\hline $\begin{array}{l}\text { Automotive } \\
\text { engine oil }\end{array}$ & $400-800$ & $0.02-0.14$ & $0.01-0.07$ & $12-18$ & $1.1-1.2$ & 36 \\
\hline
\end{tabular}

(a) Total gas production including syngas

Data summarised in Table 6 clearly demonstrated that larger syngas volumes (ca. 76\%) were produced in the biochar experiment as compared to $60 \%$ syngas using graphite 
powder as microwave captor (in which more $\mathrm{CO}_{2}$ was observed, see also ESI). Different amounts of microwave absorber were also investigated to further ascertain any catalytic effects in the systems. The increase in quantity of microwave captor (from $30 \mathrm{wt} . \%$ to 50 wt.\%) caused no significant variation in syngas yield (from 0.51 ln.c./g of algae to 0.48 ln.c./g, see ESI).

Table 6. Gas composition of MIP experiments conducted at $400^{\circ} \mathrm{C}$ using different microwave captors and proportions. ${ }^{\mathrm{a}}$

\begin{tabular}{lccc}
\hline & 400MIP & 400MIP-G & 400MIP-50 \\
\hline $\mathrm{H}_{2}$ & 57 & 50 & 58 \\
$\mathrm{CH}_{4}$ & 2 & 5 & 2 \\
$\mathrm{CO}_{2}$ & 22 & 34 & 25 \\
$\mathrm{C}_{2} \mathrm{H}_{4}$ & 1 & 1 & 0 \\
$\mathrm{C}_{2} \mathrm{H}_{6}$ & 0 & 1 & 0 \\
$\mathrm{CO}$ & 19 & 10 & 16 \\
\hline Syngas & 76 & 60 & 74 \\
$\left(\mathrm{H}_{2}+\mathrm{CO}\right)$ & 3.0 & 4.8 & 3.7 \\
\hline $\mathrm{H}_{2} / \mathrm{CO}$ & & \\
\hline a $400 \mathrm{MIP}: 30$ wt $\%$ biochar as mw captor; $400 \mathrm{MIP}-$ \\
G: 30 wt\% & commercial & graphite as & mw captor; \\
400MIP-50: 50 wt\% biochar as mw captor.
\end{tabular}

These findings therefore support a contribution of in-situ catalytic reforming of the produced gaseous products using biochar pyrolysis residues (as microwave receptor) under MIP. Elemental analysis of such MIP macroalgae derived biochar (Table 7) further confirmed the presence of important concentrations of certain transition metals including $\mathrm{Al}, \mathrm{Fe}$ and $\mathrm{Mn}$ (see also Table $2 \mathrm{~S}$ in ESI for full details). These metals can 
certainly promote reforming and cracking reactions during pyrolysis. Important amounts of some alkali metals and alkali earths $(\mathrm{K}, \mathrm{Na}, \mathrm{Mg})$ can also promote the water gas shift reaction. However, the low content of such metals (except for K) under the operating temperatures can be expected to have a relatively low influence in this reaction.

Table 7. Elemental analysis of the biochar residue after $\mathrm{CP}$ at $800^{\circ} \mathrm{C}$ of Gracilaria gracilis

\begin{tabular}{cc}
\hline Metal & Concentration (wt.\%) \\
\hline $\mathrm{Al}$ & 0.30 \\
$\mathrm{Si}$ & 1.49 \\
$\mathrm{Mn}$ & 0.15 \\
$\mathrm{Fe}$ & 0.21 \\
$\mathrm{Na}$ & 2 \\
$\mathrm{Mg}$ & 0.5 \\
$\mathrm{~K}$ & 12 \\
\hline
\end{tabular}

XRD patterns of the residue also confirmed a relatively high crystallinity of the residue in which a combination of mixed metal oxide species of $\mathrm{Mn}$, Si and Al were found to be present (Figure 4). This biochar was also found to be porous when the pyrolysis process is carried out using microwave heating. The surface areas are in the range of 40 to $110 \mathrm{~m}^{2} \mathrm{~g}^{-1}$ depending on the MIP temperature and essentially microporous in nature (see also Table 3S in ESI for full details). In this sense, microwave heating also favours the development of the porous structure of the char, when it is compared with the conventional heating. In the case of conventional heating, no porous development take place at $400^{\circ} \mathrm{C}$ whereas extremely low BET surface was found at $800^{\circ} \mathrm{C}$. This improvement in the porosity development should be also due to the pseudo-catalytic 
effect of the microplasmas. Further in-depth investigations are currently ongoing to ascertain the crystalline phases present in the biochar and potential applications of this material in catalytic processes (e.g. oxidation, reforming, etc.) that will be reported in due course.

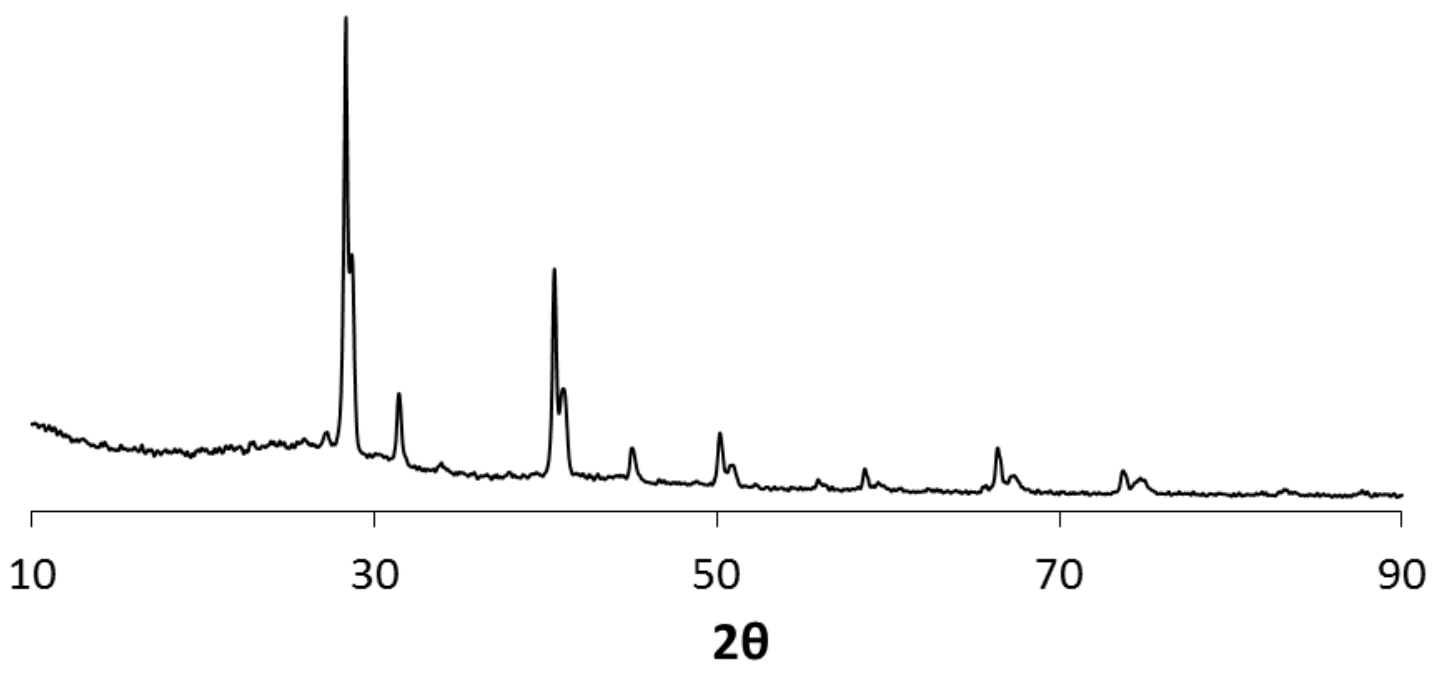

Figure 4. XRD pattern of the $\mathrm{CP}$ residue at $800^{\circ} \mathrm{C}$ used as microwave absorber

\section{Conclusions}

We have reported for the first time an innovative alternative low temperature microwave induced pyrolysis from an algal residue able to provide high syngas yields with remarkably improved hydrogen content and tunable $\mathrm{H}_{2} / \mathrm{CO}$ ratios from 3 to 1 depending on the investigated conditions. The use of the pyrolysis biochar residue (after $\mathrm{CP}$ ) as microwave absorber was found to exert and unprecedented (pseudo)-catalytic effect able to provide an optimum hydrogen production with respect to a pure graphite material employed as comparison. The proposed methodology clearly highlights the potential of MIP as compared to CP in terms of flexibility, versatility, applicability and the possibility to work at significantly lower pyrolysis temperatures with improved performance. Further studies are currently ongoing to investigate the possibility to 
provide an additional versatility to the protocol by macroalgae sampling in different seasons with the aim to also demonstrate the remarkable potential of algae-derived residues as a resource for the production of high added-value compounds.

\section{Acknowledgments}

Financial support from the European Union Seventh Framework Programme (FP7/2007-2013) under agreement $\mathrm{n}^{\mathrm{o}} 311815$ is acknowledged. JMB acknowledges the support received from the CSIC JAE Program. EGC also acknowledges a predoctoral research Grant from FICYT. RL gratefully acknowledges Ministerio de Ciencia e Innovación, Gobierno de España for the concession of a Ramon y Cajal contract (ref. RYC-2009-04199) and funding under project CTQ2011-28954-C02-02 as well as Consejeria de Ciencia e Innovación, Junta de Andalucía for funding under project P10-FQM-6711. Matteo Francavilla gratefully acknowledges the European Commission, Directorate-General for Research \& Innovation, for funding the project “STAR*AgroEnergy” (FP7 Regpot 2011-1, Grant Agreement N²86269).

\section{References}

[1] R. Luque, L. Herrero-Davila, J.M. Campelo, J.H. Clark, J.M. Hidalgo, D. Luna, J.M. Marinas, A.A. Romero, Energy Environ. Sci. 2008, 1, 542-564.

[2] M. Alvarado-Morales, A. Boldrin, D.B. Karakashev, S.L Holdt, I. Angelidaki, T. Astrup, Bioresour. Technol. 2013, 129, 92-99.

[3] D.M. Anderson, Nature 1997, 388, 513-514.

[4] a) N. Wei, J. Quarterman, Y.S. Jin, Trends Biotechnol. 2013, 31, 70-77; b) C. Zamalloa, N. Boon, W. Verstraete, Appl. Energy 2012, 92, 733-738; c) S. Tedesco, K.Y. Benyounis, A.G. Olabi, Energy 2013, 
http://dx.doi.org/10.1016/j.energy.2013.01.071; d) C.H. Vanegas, J. Bartlett, Environ. Technol. 2013, DOI: 10.1080/09593330.2013.765922.

[5] FAO 1997. Renewable biological systems for alternative sustainable energy production, 1997. Food and Agriculture Organization of the United Nations (FAO), Agricultural Services Bulletin - 128 ISBN 92-5-104059-1.

[6] a) D. Sahoo, G. Elangbam, S.S. Devi, Phykos 2012, 42, 32-38; b) F.M. Kerton, Y. Liu, K.W. Omaria, K. Hawboldt, Green Chem. 2013, DOI: 10.1039/c3gc36994c

[7] A.J. Wargacki, E. Leonard, M.N. Win, D.D. Regitsky, C.N.S. Santos, P.B. Kim, S.R. Cooper, R.M. Raisner, A. Herman, A.B. Sivitz, A. Lakshmanaswamy, Y. Kashiyama, D. Baker, Y. Yoshikuni, Science 2012, 335, 308-313.

[8] a) S. Kadam, P. Prabhasankar, Food Res. Int. 2010, 43, 1975-1980; b) P.M. Foley, E.S. Beach, J.B. Zimmerman, Green Chem. 2011, 13, 1399-1405 ; c) M. Francavilla, A. Pineda, C.S.K. Lin, M. Franchi, P. Trotta, A.A. Romero, R. Luque, Carbohydrate Polym. 2013, 92, 1555-1560.

[9] a) Y. Khambhaty, K. Mody, M.R. Gandhi, S. Thampy, P. Maiti, H. Brahmbhatt, K. Eswaran, P.K. Ghosh, Bioresour. Technol. 2012, 103, 180-185; b) J.M. Adams, T.A. Toop, J.M. Gallagher, I.S. Donnison, Bioresour. Technol. 2011, 102, 9976-9984; c) N.J. Kim, H. Li, K. Jung, H.N. Chang, P.C. Lee, Bioresour. Technol. 2011, 102, 7466-7469; d) J.-H. Park, J.-Y. Hong, H.C. Jang, S.G. Oh, S.-H. Kim, J.J. Yoon, Y.J. Kim, Bioresour. Technol. 2012, 108, 83-88; e) S. Kumar, R. Gupta, G. Kumar, D. Sahoo, R.C. Kuhad, Bioresour. Technol. 2013, http://dx.doi.org/10.1016/j.biortech.2012.10.120.

[10] a) J.E. Cloern, Mar. Ecol. Prog. Ser. 2001, 210, 223-253; b) D.M. Anderson, P.M. Glibert, J.M. Burkholder, Estuaries 2004, 25, 704-726 and references therein. 
[11] a) E. Graneli, M. Weberg, P.S. Salomon, Harmful Algae 2008, 8, 94-102; b) A.A. de la Cruz, D.D. Dionysiou, J. Westrick, Toxicon 2010, 55, 907-908 and references therein.

[12] A.B. Ross, J.M. Jones, M.L. Kubacki, T. Bridgeman, Bioresour. Technol. 2008, 99, 6494-6504.

[13] T.N. Trinh, P.A. Jensen, K. Dam-Johansen, N.O. Knudsen, H.R. Sørensen, S. Hvilsted, Energy Fuel 2013, dx.doi.org/10.1021/ef301927y.

[14] V.L. Budarin, Y. Zhao, M.J. Gronnow, P.S. Shuttleworth, S.W. Breeden, D.J. MacQuarrie, J.H. Clark, Green Chem. 2011, 13, 2330-2333.

[15] Y. Zhuang, J. Guo, L. Chen, D. Li, J. Liu, N. Ye, Bioresour. Technol. 2012, 116, $133-139$.

[16] a) L. Brennan, P. Owende, Renew. Sust. Energy Rev. 2010, 14, 557-577; b) A. Campanella, R. Muncrief, M.P. Harold, D.C. Griffith, N.M. Whitton, R.S. Weber, Bioresour. Technol. 2012, 109, 154-162.

[17] a) A. Domínguez, J.A. Menéndez, Y. Fernández, J.J. Pis, J.M.V. Nabais, P.J.M. Carrott, M.M.L.R. Carrott, J. Anal. Appl. Pyrolysis 2007, 79(1-2 SPEC. ISS.), 128-135; b) A. Domínguez, Y. Fernández, B. Fidalgo, J.J. Pis, J.A. Menéndez, Chemosphere 2008, 70, 397-403; c) R. Luque, J. A. Menendez, A. Arenillas, J. Cot, Energy Environ. Sci. 2012, 5, 5481-5488.

[18] a) Y. Fernández, A. Arenillas, M.A. Díez, J.J. Pis, J.A. Menéndez, J. Anal. Appl. Pyrolysis 2009, 84, 145-150; b) A. Domínguez, J.A. Menéndez, M. Inguanzo, J.J. Pis, Fuel Process. Technol. 2005, 86, 1007-1020.

[19] J. Fan, M. D Bruyn, V.L. Budarin, M.J. Gronnow, P.S. Shuttleworth, S. Breeden, D.J. Macquarrie, J.H. Clark, J. Am. Chem. Soc. 2013, 135, 11728-11731. 
[20] a) L. Chen, D.D. Dionysiou, K. O’ Shea, Environ. Sci. Technol. 2011, 45, 22932300; b) X.X. He, M. Pelaez, J.A. Westrick, K.E. O’Shea, A. Hiskia, T. Triantis, T. Kaloudis, M.I. Stefan, A.A. de la Cruz, D.D. Dionysiou, Water Res. 2012, 46, 15011510.

[21] J.A. Menéndez, E.M. Menéndez, A. García, J.B. Parra, J.J. Pis, J. Microwave Power Electromag. Energy 1999, 34, 137-143.

[22] a) I. Wender, Fuel Process. Technol. 1996, 48, 189-297 ; b) P. Neumann, S.C. Teuner, F. Von Linde, Oil Gas Eur. Mag. 2001, 27, 44-46 ; c) http://www.synpol.org/ [23] a) W. Chen, B. Gutmann, C.O. Kappe, Chem. Open 2012, 1, 39-48; b) B. Gutmann, A.M. Schwan, B. Reichart, C. Gspan, F. Hofer, C.O. Kappe, Angew. Chem. Int. Ed. 2011, 50, 7636-7640.

[24] J.A. Menéndez, E.J. Juárez-Pérez, E. Ruisánchez, J.M. Bermúdez, A. Arenillas, Carbon 2011, 49, 346-349.

[25] Y. Fernández, J.A. Menéndez, J. Anal. Appl. Pyrolysis 2011, 91, 316-322

[26] J.A. Menéndez, A. Domínguez, M. Inguanzo, J.J. Pis, J. Anal. Appl. Pyrolysis 2004, 71, 657-667.

[27] a) A. Domínguez, J.A. Menéndez M. Inguanzo, J.J. Pis, Bioresour. Technol 2006, 97, 1185-1193; b) L. Fang, S. Li, N. Yuan, X. Zhao, Adv Mater Res 2012, 550-553, $447-451$.

[28] W. Zuo, Y. Tian, N. Ren, Waste. Manag. 2011, 31, 1321-1326.

[29] J.A. Menéndez, A. Domínguez, Y. Fernández, J.J. Pis, Energy Fuel 2007, 21, 373 378.

[30] a) A.V. Yatsun, P.N. Konovalov, N.P. Konovalov, Solid Fuel Chem. 2008, 42, 187-191; b) A. Undri, S. Meini, L. Rosi, M. Frediani, P. Frediani, J. Anal. Appl. Pyrolysis 2013, 103, 149-158. 
[31] a) Y.F. Huang, W.H. Kuan, S.L. Lo, C.F. Lin, Bioresour. Technol. 2008, 99, 82528258; b) Y.F. Huang, W.H. Kuan, S.L. Lo, C.F. Lin, Bioresour. Technol. 2010, 101, 1968-1973; c) Y.F. Huang, P.T. Chiueh, W.H. Kuan, S.L. Lo, Bioresour. Technol. 2013, 142, 620-624-1973

[32] X.H.Wang, H.P. Chen, X.J. Ding, H.P. Yang, S.H. Zhang, Y.Q. Shen, Bioresour. $2009,4,946-949$

[33] a) X. Zhao, Z. Song, H. Liu, Z. Li, L. Li, C. Ma, J. Anal. Appl. Pyrolysis 2010, 89, 87-94; b) X. Zhao, J. Zhang, Z. Song, H. Liu, L. Li, C. Ma, J. Anal. Appl. Pyrolysis 2011, 92, 43-49.

[34] a) Z. Du, Y. Li, X. Wang, Y. Wan, Q. Chen, C. Wang, X. Lin, Y. Liu, P. Chen, R. Ruan, Bioresour. Technol. 2011, 102, 4890-4896; b) D. Beneroso, J.M. Bermúdez, A. Arenillas, J.A. Menéndez, Bioresour. Technol. 2013, 144, 240-246

[35] S. Ren, H. Lei, L. Wang, Q. Bu, S. Chen, J. Wu, J. Julson, R. Ruan, J. Anal. Appl. Pyrolysis 2012, 94, 163-169.

[36] S.S. Lam, A.D. Russell, C.L. Lee, S.K. Lam, H.A. Chase, Int. J. Hydrogen Energy 2012, 37, 5011-5021. 